\title{
Pengaruh Holding Time dan media pendingin pada proses quenching terhadap kekerasan dan kekuatan Impact pegas daun sebagai alternatif pengganti pisau slicer penuai tebu
}

\author{
Andreas Luki Indratmoko ${ }^{1}$, Eko nugroho ${ }^{2}$, Asroni ${ }^{3}$, Eko Budiyanto ${ }^{4}$ \\ Jurusan Teknik Mesin, Fakultas Teknik, Universitas Muhammadiyah Metro 1,2,3,4 \\ JI. Ki Hajar Dewantara 15 A Kota Metro, Lampung, Indonesia \\ "Coresponding author: eko_budiyanto99@yahoo.com
}

\begin{abstract}
In the process of harvesting sugarcane at a sugar factory, the Sugarcane Harvester is a tractor used to harvest sugarcane equipped with a slicer knife. Nowadays slicers are still imported from abroad, and the availability is scarce and the price is still expensive. One of the efforts to find an alternative to the slicer is to use leaf springs by hardening the metal through a heat-treatment process. Namely the process of heating steel to temperatures above the critical area followed by rapid cooling called quenching. The purpose of this study was to determine the effect of holding time and the effect of cooling media on the hardness and impact strength of leaf springs and to determine the ideal holding time and the most optimal cooling media to increase the hardness and impact strength of leaf springs. As for the research method, the spring leaves were heat-treated with a temperature of $8500 \mathrm{C}$ for 30 minutes and 60 minutes and then cooled using oil, saltwater, and water as media. The method used is observation, literature study, testing, and documentation. The results obtained from this study were at a temperature of $8500 \mathrm{C}$ with a holding time of 30 minutes the best hardness value was 477 VHN and 0.42\% increase, the best impact strength value was $0.03433 \mathrm{~J} \mathrm{/} \mathrm{mm2} \mathrm{and} 87.71 \%$ decrease, and the two cooling media, namely oil. At a temperature of $8500 \mathrm{C}$ with a holding time of 60 minutes the best hardness value was 534 $V H N$ and $12.42 \%$ increase, the best value of impact strength was $0.03203 \mathrm{~J} / \mathrm{mm} 2$ and $88.53 \%$ decrease, and the two cooling media were oil as well. So that oil is the most optimal medium for changing the mechanical properties of the Sugarcane Harvester slicer because the oil can carry a carbon layer from the cooling process that takes place and the cooling rate of the oil is not too fast from the cooling media of brine and water because of its viscosity.
\end{abstract}

Keywords: Holding Time, Cooling Media, Hardness, Impact Strength.

\begin{abstract}
Abstrak
Dalam proses pemanenan tebu di pabrik gula, Sugarcane Harvester merupakan traktor yang digunakan untuk memanen tebu dilengkapi pisau potong/slicer. Slicer selama ini masih diimport dari luar negeri, sehingga ketersediaan langka dan harganya masih mahal. Salah satu usaha untuk mendapatkan alternatif pengganti slicer adalah dengan menggunakan pegas daun dengan melakukan pengerasan pada logam tersebut melalui proses heat treatment. Yaitu proses pemanasan baja sampai suhu di diatas daerah kritis di susul dengan pendinginan yang cepat dinamakan quenching. Tujuan penelitian ini untuk mengetahui pengaruh holding time dan pengaruh media pendinginan terhadap kekerasan dan kekuatan impact pegas daun, serta mengetahui holding time ideal dan media pendingin yang paling optimal untuk meningkatkan kekerasan dan kekuatan impact pegasdaun. Adapun metode penelitianya pegasdaun tersebut diberi perlakuan panas dengan temperatur $850^{\circ} \mathrm{C}$ selama 30 menit dan 60 menit lalu didinginkan menggunakan media oli, air garam, dan air. Metode yang dilakukan adalah
\end{abstract}


observasi, study literatur, pengujian, serta dokumentasi. Hasil yang diperoleh dari penelitian ini adalah pada temperatur $850^{\circ} \mathrm{C}$ dengan holding time 30 menit nilai kekerasan yang terbaik adalah 477 VHN dan $0,42 \%$ kenaikan, nilai kekutan impact yang terbaik adalah 0,03433 $\mathrm{J} / \mathrm{mm} 2$ dan $87,71 \%$ penurunan, dan kedua media pendingin tersebut yaitu oli. Pada temperatur $850^{\circ} \mathrm{C}$ dengan holding time 60 menit nilai kekerasan yang terbaik adalah 534 VHN dan $12,42 \%$ kenaikan, nilai kekuatan impact yang terbaik adalah $0,03203 \mathrm{~J} / \mathrm{mm} 2$ dan $88,53 \%$ penurunan, dan kedua media pendingin tersebut yaitu oli juga. Sehingga oli adalah media yang paling optimal untuk perubahan sifat mekanik slicer Sugarcane Harvester karena pada oli dapat membawa lapisan karbon dari proses pendinginan yang berlangsung dan laju pendinginan dari oli tidak terlalu cepat dari media pendingin air garam dan air karena viskositas atau kekentalannya.

Kata Kunci : Holding Time, Media Pendingin, Kekerasan, Kekuatan Impact.

\section{Pendahuluan}

Proses menuai atau memanen batang tebu di perusahaan gula menjadi suatu hal yang wajib diperhitungkan, terkait biaya dan waktu prosesnya sehingga bisa berjalan semakin efektif. Sugarcane harvester merupakan alat yang digunakan untuk proses pemanenan batang tebu yang sangat efektif yang sampai saat ini digunakan perusahaan-perusahaan gula. Kebutuhan pisau penuai (slicer) yang terbuat dari baja pun meningkat pesat, slicer sugarcane harvester termasuk dalam kategori baja paduan yang keras dan ulet di produksi khusus dan di import dari Taiwan sehingga dari ketersediaannya cukup langka dan harganya pun cukup mahal.

Maka dari itu peneliti mencoba mengangkat permasalahan pengerasan logam pada pegas daun truk yang termasuk dalam golongan baja pegas sebagai alternatif pengganti slicer. Baja pegas daun dapat dikeraskan dan ditingkatkan keuletannya dengan beberapa cara, antara lain adalah dengan melakukan proses perlakuan panas (heat treatment) yang dapat membentuk atau merubah sifat baja dari yang mudah patah menjadi lebih kuat dan ulet atau juga dapat merubah sifat baja dari yang lunak menjadi sangat keras dan sebagainya. Dari penelitian sebelumnya sudah di peroleh data bahwa material baja pegas daun termasuk baja karbon sedang $(\mathrm{C}$ $=0,3 \%)[3]$.

Salah satu proses perlakuan panas pada baja adalah pengerasan (hardening), yaitu proses pemanasan baja sampai suhu di atas daerah kritis di susul dengan pendinginan yang cepat yang dinamakan quenching [8]. Pada penelitian ini selain material asli (raw material), juga digunakan spesimen untuk proses pemanasan, sementara slicer sugarcane harvester produksi $\mathrm{Ku}$ Lin Taiwan hanya dilakukan uji komposisi kimianya untuk menjadi dasar pemilihan pegas daun truk sebagai alternatif pengganti slicer penuai tebu. Proses hardening menggunakan temperatur yang sama, yaitu dengan temperatur $850^{\circ} \mathrm{C}$, dengan variasi holding time selama 30 menit dan 60 menit, lalu menggunakan beberapa variasi media pendinginan yaitu dengan menggunakan media air, air garam, dan oli karena ketiga media pendingin tersebut masing - masing memiliki kekhasan tersendiri. Peneliti ingin mengetahui saat dilakukan proses hardening pada holding time berapa dan media pendingin apa yang baik untuk meningkatkan hasil kekerasan dan kekuatan impact dari proses heat treatment tersebut.

Untuk mengetahui hasil dari penelitian tersebut, perlu melakukan pengujian pada bahan uji yaitu pegas daun khususnya pegas daun belakang truk. Untuk mengetahui perubahan sifat mekanik yang terjadi dimana penelitian hanya menguji kekerasan dengan menggunakan alat uji Vikers microhardness dan uji impact dengan metode Charpy.

\section{Tinjauan Pustaka}

Slicer Sugarcane Harvester merupakan suatu komponen pisau potong 
dari alat berat sugarcane harvester yang berfungsi untuk memotong pangkal batang tebu yang dipanen. Slicer terbuat dari bahan baja karbon sedang yang memiliki tingkat kekerasan tertentu yang berguna menahan laju keausan dan tingkat keuletan tertentu yang berguna menyerap beban benturan yang terjadi saat proses penuaian batang tebu, proses pembuatan dilakukan dengan metode pengecoran, tempa, dan permesinan.

Slicer dibuat sedemikian rupa sehingga dapat dipasang pada disc holder atau pemegang pisau yang melingkar berisi lima slicer dan terdiri dari dua disc holder pada setiap mesin sugarcane harvester. Masalah yang sering terjadi pada slicer yaitu keausan dan patah/pecah karena pada slicer mempunyai beban gesek dan impact yang besar saat pemotongan batang tebu dan harga yang relatif mahal. Maka dari itu penulis ingin meneliti tentang pegas daun sebagai alternatif pengganti slicer penuai batang tebu agar bisa memberikan solusi pada permasalahan yang terjadi di komponen slicer sugarcane harvester, yaitu dengan cara perlakuan panas.

Dari hasil pengujian komposisi kimia di PT. ITOKOH CEPERINDO Klaten, bahan slicer yang di produksi PT. $\mathrm{Ku}$ Lin Taiwan telah diketahui komposisi kimianya.

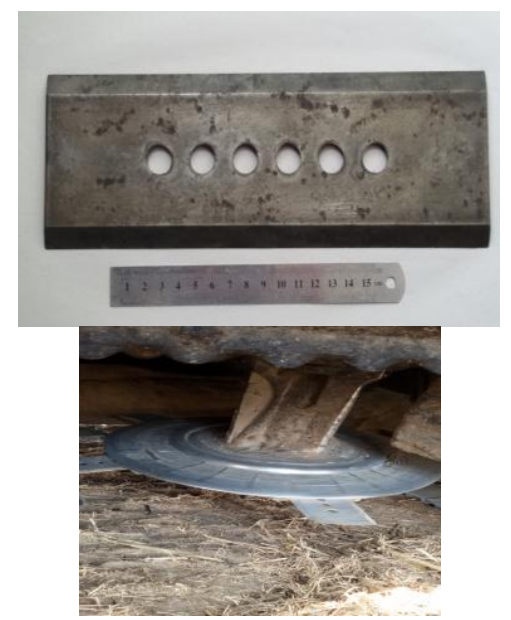

Gambar 1. Slicer Sugarcane Harvester (atas), Slicer yang terpasang pada disc holder mesin (bawah)

\section{Mekanisme kerja slicer sugarcane harvester}

Slicer Sugarcane Harvester adalah komponen utama dengan dimensi tebal 4 $\mathrm{mm}$, lebar $90 \mathrm{~mm}$ dan panjang $260 \mathrm{~mm}$ yang bekerja memotong batang tebu dengan cara dipasang pada dua buah disc holder mesin yang masing-masing berisi lima buah slicer. Batang tebu yang akan dipotong diarahkan dan diputar oleh dua feeder coloum agar masuk mendekati slicer sehingga terpotong. Setiap mesin harvester memiliki dua disc holder yang terpasang dibagian depan dan berputar saling berlawanan arah jarum jam.

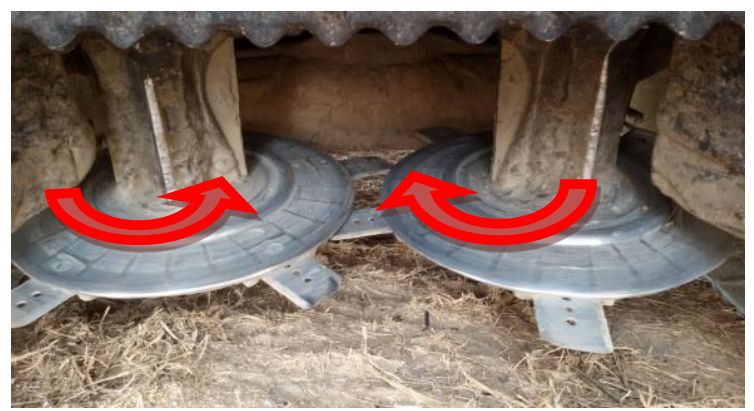

Gambar 2. Arah putaran disc holder Slicer

Sugarcane Harvester saat proses

pemotongan batang tebu saling berlawanan arah jarum jam

Pada saat spindle utama berputar, mesin/traktor harvester berjalan maju dengan kecepatan konstan sehingga batangbatang tebu akan terpotong. Tenaga dari mesin / traktor harvester disalurkan ke penggerak roda atau rantai yang dapat dipilih sesuai dengan kondisi tanah yang ada, fungsi pemotongan batang tebu bisa berjalan tidak lepas juga dari peran dua feeder coloum yang ada di depan disc holder slicer yang berputar mengarahkan batang tebu ke slicer sehingga batang tebu terpotong. Slicer sugarcane harvester digerakan dengan mesin / traktor yang memiliki tenaga yang besar yaitu sekitar 99-249 HP. 


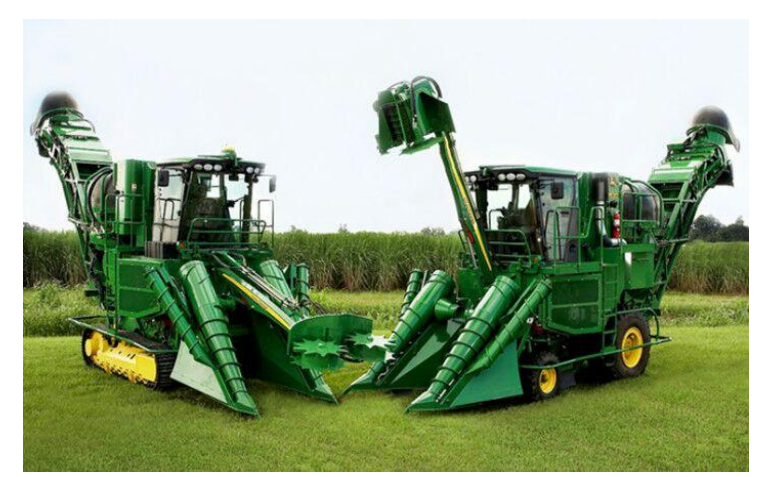

Gambar 3. John Deere Sugarcane

Harvester berpenggerak rantai (kiri) dan berpenggerak roda (kanan)

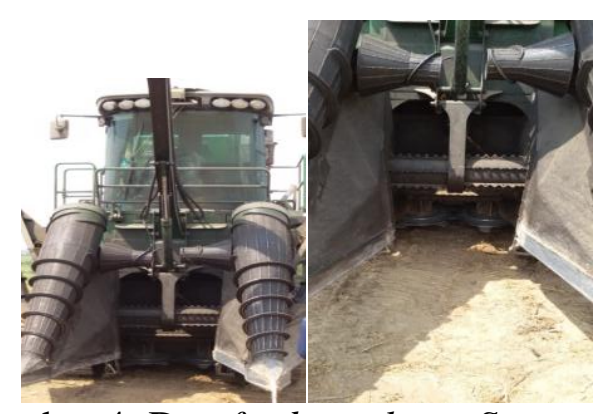

Gambar 4. Dua feeder coloum Sugarcane Harvester (kiri) yang mengarahkan batang tebu masuk ke slicer (kanan)

\section{Beban kerja pada slicer sugarcane harvester}

Pemotongan adalah suatu proses pembagian benda solid secara mekanik sepanjang garis yang diinginkan dengan menggunakan alat pemotong (Persson 1987). Dalam beberapa kasus yang ada, pemotongan mempunyai istilah yang berbeda bergantung dengan alat apa dan bagaimana pemotongan itu dilakukan. Istilah tersebut antara lain mencacah (chopping), memangkas (mowing), menggergaji (sawing), membelah (aplitting), mengiris (slicing), dan sebagainya. Ada beberapa hal penting yang mengakibatkan meningkatnya beban kerja pada slicer sugarcane harvester:

1. Ketajaman pisau merupakan salah satu faktor penting dalam pemotongan material. Ketajaman memiliki efek yang signifikan terhadap gaya pemotongan, semakin tajam pisau yang digunakan maka gaya pemotongan yang diperlukan juga semakin rendah. Begitu juga dengan sudut mata pisau, pisau yang memiliki sudut mata pisau kecil membutuhkan gaya pemotongan spesifik maksimum yang relatif rendah [15].

2. Kekerasan dan keuletan material pisau juga menjadi faktor yang penting dalam proses pemotongan tebu. Pada aplikasi pemakaiannya, semua struktur logam akan terkena pengaruh gaya luar berupa tegangan-tegangan gesek sehingga menimbulkan deformasi atau perubahan bentuk yang akan menurunkan ketangguhannya. Usaha menjaga agar logam lebih tahan gesekan atau tekanan adalah dengan cara perlakuan panas, hal ini memegang peranan penting dalam upaya meningkatkan kekerasan baja sesuai dengan kebutuhannya.

\section{Mekanisme kegagalan pada slicer sugarcane harvester}

Untuk memenuhi fungsinya maka slicer sugarcane harvester dirancang untuk dapat memotong batang-batang tebu dengan ketinggian dari tunggul sekitar 5 $\mathrm{cm}-10 \mathrm{~cm}$. Pada saat mesin sugarcane harvester melakukan proses pemotongan batang tebu, posisi ketinggian disc holder slicer dikendalikan melalui tekanan beban kerja slicer yang dikontrol melalui pressure gauge yang ada diruang kendali. Jadi ketinggian pemotongan tidak secara otomatis mengikuti kontur dari tanah namun harus dikendalikan secara manual oleh operator mesin. Tekanan kerja efektif dari disc holder dapat dibaca oleh operator pada pressure gauge, jika tekanan antara 10 bar - 15 bar maka proses pemotongan berjalan normal, namun jika tekanan diatas 15 bar maka dapat dipastikan disc holder dan slicer terbenam kedalam tanah. Kondisi dibawah tanah terkadang juga terdapat batu dan material keras lainnya sehingga slicer mengalami beban gesekan dan beban benturan yang cukup besar dan sangat dinamis.

Pada penelitian ini digunakan mesin/traktor merek John Deere 3520 Sugarcane Harvester dengan kecepatan 
maju mesin $10 \mathrm{~km} / \mathrm{jam}$ dan kecepatan 2 buah spindle utama yang masing-masing terdiri dari 5 buah slicer adalah $2000 \mathrm{rpm}$. Proses menuai tebu yang dilakukan mesin ini saat menggunakan slicer produksi PT. $\mathrm{Ku}$ Lin Taiwan menurut penelitian, ditemukan bahwa slicer yang berjumlah 10 buah untuk setiap proses penuaian dapat bertahan selama 4 jam dengan hasil kurang lebih 100 ton, setelah itu slicer harus diganti karena sudah mengalami kerusakan atau deformasi keausan dan pecah. Pada (Gambar 2.5) kerusakan atau deformasi akibat beban kerja mengakibatkan kegagalan fungsi slicer yaitu keausan dan pecah akibat benturan dengan meterial keras didalam tanah.

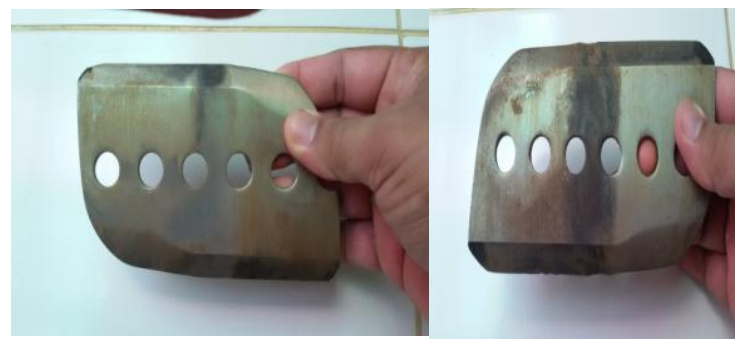

Gambar 5. Slicer Sugarcane Harvester

mengalami aus (kiri) dan mengalami aus dan pecah (kanan)

\section{Baja pegas (spring steel)}

Pegas daun (Leaf Spring) adalah suatu komponen yang berfungsi untuk menerima beban dinamis dan memberikan kenyamanan dalam kendaraan bermotor. Dengan kondisi pembebanan yang diterima tersebut, material pegas daun harus memiliki kekuatan elastic tinggi dan diimbangi juga dengan ketangguhan yang tinggi. Salah satu pegas yang umum digunakan pada kendaraan bermotor roda empat adalah pegas daun. Pada aplikasinya pegas daun umumnya digunakan pada bagian roda belakang. Jenis model pegas yang ada sangatlah bermacam-macam, diantaranya pegas daun, pegas helix, pegas torsi, pegas cakram dan lain-lain. Jenisjenis pegas tersebut memiliki karakteristik yang berbeda satu dan lainya. Disamping itu juga memiliki perbedaan pada material yang digunakan dan sifat mekaniknya, Hal ini disesuaikan dengan standar proses pembuatan pegas yang ada. Salah satu material dasar yang digunakan untuk pegas daun adalah JIS SUP 9A. Material JIS SUP 9A mempunyai kekuatan tarik yang tinggi, kekuatan elastic yang baik dan ketahanan terhadap korosi yang lebih baik dari baja karbon lainnya (Rabiatul Adawiyah, 2014). Pada proses produksi material JIS SUP 9A ini, proses perlakuan panas merupakan bagian dari proses finishing, agar sifat mekanik akhir dari material tersebut akan menjadi lebih baik dari material awal. Menurut JIS G 4801, 1981. Baja SUP dibagi menjadi sembilan grade, dapat dilihat pada Tabel 1.

Tabel 1. Pembagian baja SUP dan penggunaannya.

\begin{tabular}{|c|c|c|}
\hline \multicolumn{2}{|c|}{ Designation of grade } & \multirow{2}{*}{$\begin{array}{l}\text { Remark } \\
\text { Mainly used for } \\
\text { laminated }\end{array}$} \\
\hline SUP 3 & $\begin{array}{l}\text { High Carbon } \\
\text { Steel }\end{array}$ & \\
\hline SUP 6 & \multirow{4}{*}{$\begin{array}{l}\text { Silicon } \\
\text { Manganese } \\
\text { Steel } \\
\text { Manganese } \\
\text { Chromium } \\
\text { Steel }\end{array}$} & \multirow{4}{*}{$\begin{array}{l}\text { Mainly used for } \\
\text { laminated spring, } \\
\text { coiled spring, and } \\
\text { torsion bar spring. }\end{array}$} \\
\hline SUP 7 & & \\
\hline SUP 9 & & \\
\hline SUP9A & & \\
\hline SUP 10 & $\begin{array}{l}\text { Chromium } \\
\text { Vanadium } \\
\text { Steel }\end{array}$ & $\begin{array}{l}\text { Mainly used for } \\
\text { coiled spring, and } \\
\text { torsion bar spring. }\end{array}$ \\
\hline $\begin{array}{l}\text { SUP } \\
11 \mathrm{~A}\end{array}$ & $\begin{array}{l}\text { Manganese } \\
\text { Chromiun } \\
\text { Boron Steel }\end{array}$ & $\begin{array}{l}\text { Mainly used for } \\
\text { laminated spring, } \\
\text { coiled spring, and } \\
\text { torsion bar spring. }\end{array}$ \\
\hline SUP 12 & $\begin{array}{l}\text { Silicon } \\
\text { Chromium } \\
\text { Steel }\end{array}$ & $\begin{array}{l}\text { Mainly used for } \\
\text { spring. }\end{array}$ \\
\hline SUP 13 & $\begin{array}{l}\text { Chromium } \\
\text { Molybdenum } \\
\text { Steel }\end{array}$ & $\begin{array}{l}\text { Mainly used for } \\
\text { laminated spring and } \\
\text { coiled spring. }\end{array}$ \\
\hline
\end{tabular}

Dari hasil pengujian komposisi kimia, bahan pegas daun truk bekas tebal $14 \mathrm{~mm}$ telah diketahui komposisi kimianya, yaitu sebagai berikut;

Tabel 2. Komposisi kimia pegas daun truk bekas tebal $14 \mathrm{~mm}$.

\begin{tabular}{cccc}
\hline $\begin{array}{c}\text { Unsur } \\
\text { Kimia }\end{array}$ & \% Unsur & $\begin{array}{c}\text { Unsur } \\
\text { Kimia }\end{array}$ & $\begin{array}{c}\% \\
\text { Unsur }\end{array}$ \\
\hline $\mathrm{Fe}$ & 96,9900 & $\mathrm{~W}$ & $-0,0002$ \\
\hline $\mathrm{S}$ & 0,0179 & $\mathrm{P}$ & 0,0155 \\
\hline $\mathrm{Al}$ & 0,0088 & $\mathrm{Cu}$ & 0,0557 \\
\hline
\end{tabular}




\begin{tabular}{cccc}
\hline $\mathrm{C}$ & 0,5597 & $\mathrm{Ti}$ & 0,0077 \\
\hline $\mathrm{Ni}$ & 0,0314 & $\mathrm{~N}$ & 0,0290 \\
\hline $\mathrm{Si}$ & 0,3540 & $\mathrm{~Pb}$ & 0,0080 \\
\hline $\mathrm{Cr}$ & 0,9287 & $\mathrm{Sb}$ & 0,0074 \\
\hline $\mathrm{V}$ & 0,0050 & $\mathrm{Ca}$ & 0,0000 \\
\hline $\mathrm{Mn}$ & 0,9111 & $\mathrm{Mg}$ & 0,0003 \\
\hline $\mathrm{Mo}$ & 0,0024 & $\mathrm{Zn}$ & 0,0001 \\
\hline
\end{tabular}

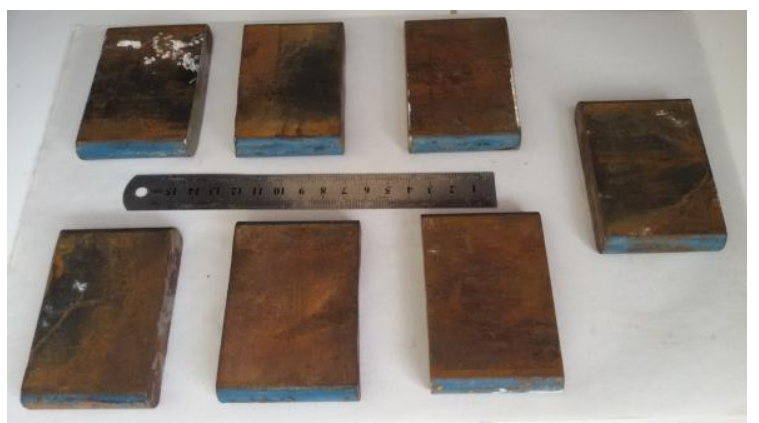

Gambar 6. Potongan pegas daun truk bekas tebal $14 \mathrm{~mm}$.

\section{Waktu penahanan (holding time)}

Holding time dilakukan untuk mendapatkan kekerasan maksimum dari suatu bahan pada proses hardening dengan menahan pada temperatur pengerasan untuk memperoleh pemanasan yang homogen sehingga struktur austenitnya homogen atau terjadi kelarutan karbida ke dalam austenit dan difusi karbon dan unsur paduannya (Margono, 2008). Pada saat tercapainya temperatur kritis atas, struktur sudah hampir seluruhnya austenit. Tetapi pada saat itu austenit masih berbutir halus dan kadar karbon serta unsur paduannya belum homogen dan biasanya masih ada karbida yang belum larut. Untuk itu baja perlu ditahan pada temperatur austenit beberapa saat untuk memberi kesempatan larutnya karbida dan lebih homogennya austenit. Dan lamanya waktu penahan ini tergantung pada :

1. Tingkat kelarutan karbida.

2. Ukuran butir yang diinginkan.

3. Laju pemanasan.

4. Ketebalan spesimen (ukuran penampang).

\section{Media pendingin quenching}

Media pendingin yang digunakan untuk mendinginkan baja bermacammacam. Berbagai bahan pendingin yang digunakan dalam proses perlakuan panas antara lain :

1. Air

Pendinginan dengan mengguna kan air akan memberikan daya pendinginan yang cepat. Air memiliki karakteristik yang khas yang tidak dimiliki oleh senyawa yang lain. Karakteristik tersebut adalah sebagai berikut [1]. Konduktivitas termal air yaitu $0,556 \mathrm{k}\left(\mathrm{w} / \mathrm{m} . \mathrm{C}^{0}\right)$. Pada kisaran suhu yang sesuai bagi kehidupan, yakni $0^{0} \mathrm{C}\left(32^{0} \mathrm{~F}\right)-100^{\circ} \mathrm{C}$, air berwujud cair. Suhu $0^{0} \mathrm{C}$ merupakan titik beku ( freezing point) dan suhu $100^{\circ} \mathrm{C}$ merupakan titik didih ( boiling point ) air.

Perubahan suhu air berlangsung lambat sehingga air memiliki sifat sebagai penyimpan panas yang sangat baik. Sifat ini memungkinkan air tidak menjadi panas atau dingin dalam seketika [1].

2. Pelumas oli SAE 40

Pelumas yang digunakan sebagai fluida pendingin dalam perlakuan panas adalah yang dapat memberikan lapisan karbon pada permukaan benda kerja yang diolah, untuk konduktivitas termal oli $0,147 \quad \mathrm{k} \quad\left(\mathrm{w} / \mathrm{m} . \quad \mathrm{C}^{0}\right)$. Viskositas oli dan bahan dasar oli membawa pengaruh dalam mendinginkan spesimen.

Ada tiga faktor yang mempengaruhi viskositas, yaitu komposisi, suhu, dan tekanan. Angka viskositas biasanya ditinjai dengan SAE (Society of Automotive Engine) dan disertai angka. Angka menunjukan pada kelompok mana visikositas itu termasuk [2].

Dengan adanya perkembangan teknologi lebih dari satu tingkat klasifikasi viskositasnya yang dikenal dengan minyak pelumas multigrade. Penulisan angka viskositas misalnya SAE 10W - 40 dengan maksud standar olinya SAE $10 \mathrm{~W}$ pada suhu $20^{\circ} \mathrm{C}$ dan standar SAE 40 pada suhu $100^{\circ} \mathrm{C}$. Sehingga pelumas ini bila digunakan 
dalam lingkungan suhu dingin akan bersikap sebagai pelumas SAE 10W sedangkan bila digunakan dalam lingkungan suhu panas akan bersikap sebagai minyak pelumas SAE 40 [2].

3. Air garam

Air garam dipakai sebagai bahan pendingin disebabkan memiliki sifat mendinginkan yang teratur dan cepat, konduktivitas termal air garam 0,518 $\mathrm{k}\left(\mathrm{w} / \mathrm{m} . \mathrm{C}^{0}\right)$. Bahan yang didinginkan didalam cairan garam yang akan mengakibatkan ikatannya menjadi lebih keras karena pada permukaan benda kerja tersebut akan meningkat zat arang [1].

\section{Metode Penelitian}

Alur Penelitian dapat dijelaskan sebagai berikut;

1. Penyiapan Bahan

2. Bahan yang digunakan dalam penelitian ini adalah baja pegas daun jenis truk 8 DC 9 Mitsubishi berbentuk pelat memanjang.

3. Pembuatan Benda Uji

4. Pemotongan bahan dengan ketebalan 10 $\mathrm{mm}$, menggunakan gerinda mesin pendinginan dengan air untuk menjaga kestabilan struktur internal agar tidak panas. Adapun benda uji penelitian berjumlah 26 buah, masing-masing 19 buah untuk pengujian impact dan 7 buah untuk pengujian kekerasan. Sedangkan masing-masing diambil 1 (satu) buah sebagai pembanding atau raw material.

5. Pengujian Komposisi Kimia

6. Pengujian ini dilakukan untuk memeriksa dan mengetahui jumlah (prosentase) kandungan unsur paduan yang terdapat pada spesimen, terutama kadar unsur karbon (C).

7. Perlakuan Panas

8. Perlakuan panas dengan menggunakan dapur pemanas (furnace), pada temperatur pema- nasan $850^{\circ} \mathrm{C}$ dan waktu tahan 30 menit dan 60 menit.

9. Alat-alat dan bahan yang digunakan antara lain: dapur pemanas (furnace), sedangkan media quenching: air tawar suhu ruang, garam $\mathrm{NaCl}$ dan oli.

10. Pengujian Impact

11. Pengujian ini bertujuan untuk mengetahui keuletan dan ketahanan benda uji terhadap beban dinamis. Uji impact digunakan metode Charpy

12. Pengamatan dilakukan di bawah mikroskop Olympus Metallurgical Microscope dengan pembesaran 200x dan 500x, sedangkan untuk pemotretan dilakukan dengan tambahan alat Olympus Photomicrographic System.

13. Pengujian Kekerasan

14. Pengujian kekerasan pada penelitian ini adalah menggunakan uji kekerasan Micro Hardness Vickers. Alat yang digunakam adalah Micro Hardness Tester. Indentor (penetrator) yang digunakan berupa piramida intan dengan bermacam-macam diameter. Diagonaldiagonal piramida yang digunakan adalah d1 (mm) dan d2 (mm). Sedangkan beban penekanan yaitu 100 kgf dengan waktu pembebanan selama \pm 10 detik.

\section{Hasil dan Pembahasan}

Setelah pembentukan benda uji (spesimen) yang terdiri dari 7 kelompok material dan pelaksanaan perlakuan panas dengan temperatur $850^{\circ} \mathrm{C}$ dengan waktu tahan selama 30 menit dan 60 menit. Dan metode quenching dengan 3 variabel media pendingin air, air garam, dan oli selanjutnya dilakukan uji sifat mekanis meliputi uji kekerasan dan uji impact. Untuk memudahkan dalam membaca, material yang digunakan untuk penelitian ini diberikan pengkodean sebagai berikut:

Tabel 3. Kode Material Pengujian

\begin{tabular}{ccl}
\hline No & $\begin{array}{c}\text { Kode } \\
\text { Material }\end{array}$ & \multicolumn{1}{c}{ Jenis Material } \\
\hline 1 & A0 & Tanpa Perlakuan Panas \\
\hline 2 & B1 & $\begin{array}{l}\text { Pendinginan Oli Dengan Temperatur } \\
850^{\circ} \mathrm{C} \text { Dan Holding Time 30 menit }\end{array}$ \\
\hline 3 & B2 & $\begin{array}{l}\text { Pendinginan Air Garam Dengan } \\
\text { Temperatur } 850^{\circ} \mathrm{C} \text { Dan Holding Time } \\
30 \text { menit }\end{array}$ \\
\hline 4 & B3 & $\begin{array}{l}\text { Pendinginan Air Dengan Temperatur } \\
850^{\circ} \mathrm{C} \text { Dan Holding Time 30 menit }\end{array}$ \\
\hline
\end{tabular}




\begin{tabular}{cll}
\hline 5 & $\mathrm{C} 1$ & $\begin{array}{l}\text { Pendinginan Oli Dengan Temperatur } \\
850^{\circ} \mathrm{C} \text { Dan Holding Time 60 menit }\end{array}$ \\
\hline 6 & $\mathrm{C} 2$ & $\begin{array}{l}\text { Pendinginan Air garam Dengan } \\
\text { Temperatur } 850^{\circ} \mathrm{C} \text { Dan Holding Time } \\
60 \text { menit }\end{array}$ \\
\hline 7 & $\mathrm{C} 3$ & $\begin{array}{l}\text { Pendinginan Air Dengan Temperatur } \\
850^{\circ} \mathrm{C} \text { Dan Holding Time 60 menit }\end{array}$ \\
\hline
\end{tabular}

Hasil uji kekerasan

Pengujian kekerasan dilakukan dengan uji kekerasan Vickers Micro Hardness. Data kekerasan pada material tanpa perlakuan panas dan menggunakan perlakuan panas dengan temperatur $850^{\circ} \mathrm{C}$ menggunakan metode quenching dapat dilihat pada Tabel 4.

Tabel 4. Hasil Nilai Uji Keras Untuk Material Tanpa Perlakuan Panas

\begin{tabular}{ccccccc}
\hline $\begin{array}{c}\text { Titik } \\
\text { ke.. }\end{array}$ & $\begin{array}{c}\text { Kode } \\
\text { Material }\end{array}$ & $\begin{array}{c}\text { Diag.1 } \\
(\mathrm{mm})\end{array}$ & $\begin{array}{c}\text { Diag.2 } \\
(\mathrm{mm})\end{array}$ & $\begin{array}{c}\text { Diag. } \\
\begin{array}{c}\text { Rata- } \\
\text { rata } \\
(\mathrm{mm})\end{array}\end{array}$ & VHN & $\begin{array}{c}\text { VHN } \\
\text { Rata-rata }\end{array}$ \\
\hline 1 & A0 & 0,632 & 0,623 & 0,6275 & 471 & \\
\cline { 1 - 3 } 2 & A0 & 0,613 & 0,616 & 0,6145 & 491 & 475 \\
\cline { 1 - 2 } 3 & A0 & 0,639 & 0,628 & 0,6335 & 462 & \\
\hline
\end{tabular}

Tabel 5. Hasil Nilai Uji Keras Untuk Material Dengan Temperatur $850^{\circ} \mathrm{C}$ Dan Holding Time 30 Menit

\begin{tabular}{|c|c|c|c|c|c|c|}
\hline $\begin{array}{l}\text { Titik } \\
\text { ke.. }\end{array}$ & $\begin{array}{l}\text { Kode } \\
\text { Material }\end{array}$ & $\begin{array}{c}\text { Diag.1 } \\
(\mathrm{mm})\end{array}$ & $\begin{array}{c}\text { Diag.2 } \\
(\mathrm{mm})\end{array}$ & $\begin{array}{c}\text { Diag. } \\
\text { Rata- } \\
\text { rata } \\
(\mathrm{mm})\end{array}$ & VHN & $\begin{array}{l}\text { VHN } \\
\text { Rata-rata }\end{array}$ \\
\hline 1 & B1 & 0,626 & 0,638 & 0,632 & 464 & \multirow{3}{*}{477} \\
\hline 2 & B1 & 0,627 & 0,628 & 0,6275 & 471 & \\
\hline 3 & B1 & 0,612 & 0,609 & 0,6105 & 497 & \\
\hline 1 & B2 & 0,576 & 0,561 & 0,5685 & 574 & \multirow{3}{*}{582} \\
\hline 2 & B2 & 0,559 & 0,555 & 0,557 & 598 & \\
\hline 3 & B2 & 0,574 & 0,562 & 0,568 & 575 & \\
\hline 1 & B3 & 0,481 & 0,484 & 0,4825 & 796 & \multirow{3}{*}{794} \\
\hline 2 & B3 & 0,493 & 0,493 & 0,493 & 763 & \\
\hline 3 & B3 & 0,476 & 0,474 & 0,475 & 822 & \\
\hline
\end{tabular}

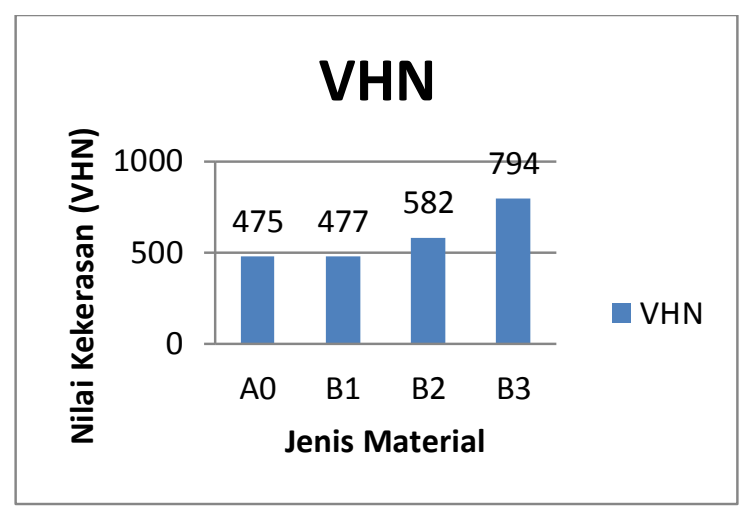

Gambar 8. Perbandingan Material Tanpa Perlakuan PanasDengan Media Pendingin Yang Berbeda Pada Temperatur $850^{\circ} \mathrm{C}$ Dengan Holding Time 30 Menit Terhadap Kekerasan

Material yang diberi perlakuan panas dengan temperatur $850^{\circ} \mathrm{C}$ dan holding time 30 menit rata-rata nilai kekerasannya terendah sebesar 477 VHN dan tertinggi 794 VHN terhadap material tanpa perlakuan panas yang hanya sebesar 475 VHN.

Pada temperatur $850^{\circ} \mathrm{C}$ dengan holding time 60 menit, nilai kekerasan material dapat dilihat dalam tabel dibawah ini.

Tabel 6. Hasil Nilai Uji Keras Untuk Material Dengan Temperatur $850^{\circ} \mathrm{C}$ Dan Holding Time 60 Menit

\begin{tabular}{|c|c|c|c|c|c|c|}
\hline $\begin{array}{l}\text { Titik } \\
\text { ke.. }\end{array}$ & $\begin{array}{l}\text { Kode } \\
\text { Material }\end{array}$ & $\begin{array}{c}\text { Diag.1 } \\
(\mathrm{mm})\end{array}$ & $\begin{array}{l}\text { Diag.2 } \\
(\mathrm{mm})\end{array}$ & $\begin{array}{c}\text { Diag. } \\
\text { Rata- } \\
\text { rata } \\
(\mathrm{mm})\end{array}$ & VHN & $\begin{array}{c}\text { VHN } \\
\text { Rata-rata }\end{array}$ \\
\hline 1 & $\mathrm{C} 1$ & 0,532 & 0,546 & 0,539 & 638 & \multirow{3}{*}{534} \\
\hline 2 & $\mathrm{C} 1$ & 0,629 & 0,621 & 0,625 & 475 & \\
\hline 3 & $\mathrm{C} 1$ & 0,612 & 0,619 & 0,6155 & 489 & \\
\hline 1 & C2 & 0,504 & 0,518 & 0,511 & 710 & \multirow{3}{*}{652} \\
\hline 2 & $\mathrm{C} 2$ & 0,571 & 0,566 & 0,5685 & 574 & \\
\hline 3 & C2 & 0,525 & 0,525 & 0,525 & 673 & \\
\hline 1 & C3 & 0,515 & 0,507 & 0,511 & 710 & \multirow{3}{*}{708} \\
\hline 2 & C3 & 0,524 & 0,524 & 0,524 & 675 & \\
\hline 3 & C3 & 0,499 & 0,502 & 0,5005 & 740 & \\
\hline
\end{tabular}

tanpa perlakuan panas terhadap material dengan media pendingin yang berbeda (air, 
air garam, dan oli) pada temperatur $850^{\circ} \mathrm{C}$ dengan holding time 60 menit.

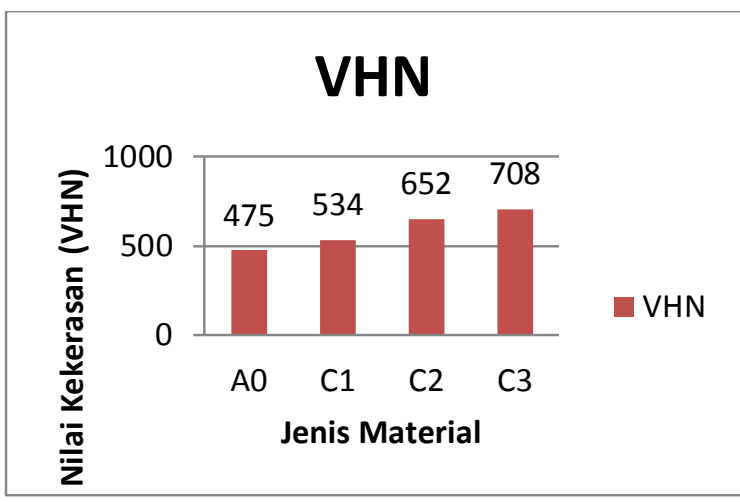

Gambar 9. Perbandingan Material Tanpa Perlakuan Panas Dengan Media Pendingin Yang Berbeda Pada Temperatur $850^{\circ} \mathrm{C}$ Dengan Holding Time 60 Menit Terhadap Kekerasan.

Material yang diberi perlakuan panas dengan temperatur $850^{\circ} \mathrm{C}$ dan holding time 60 menit nilai kekerasannya terendah sebesar 534 VHN dan tertinggi 708 VHN sedangkan pada media pendingin oli nilai kekerasanya lebih tinggi dari material tanpa perlakuan panas yaitu sebesar 534 VHN, sementara nilai kekerasan material tanpa perlakuan panas sebesar 475 VHN.

Pada grafik dibawah ini akan dijelaskan perbandingan nilai kekerasan yang paling tinggi pada setiap holding time nya.

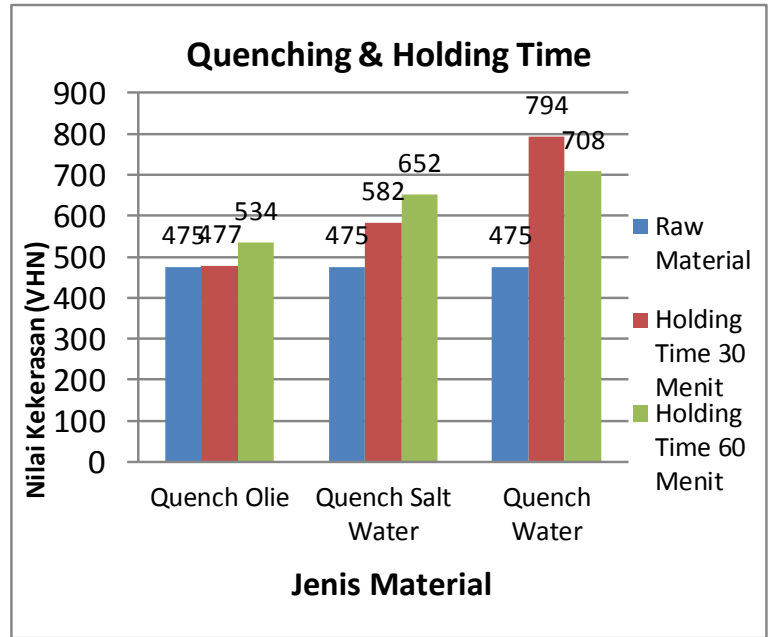

Gambar 10. Perbandingan Nilai Kekerasan Pada Setiap Holding Time Yang Berbeda
Dengan Material Tanpa Perlakuan Panas. Proses perlakuan panas pada temperatur $850^{\circ} \mathrm{C}$ dengan holding time 30 menit memiliki nilai kekerasan tertinggi sebesar 794 VHN dan pada temperatur $850^{\circ} \mathrm{C}$ dengan holding time 60 menit sebesar 708 VHN. Nilai kekerasan yang paling tinggi pada grafik ini yaitu pada temperatur $850^{\circ} \mathrm{C}$ dengan holding time 30 menit dan media pendingin air.

\section{Hasil uji impact}

Pengujian impact dilakukan dengan uji impact Charpy. Data dari pengujian impact pada material tanpa perlakuan panas dan menggunakan perlakuan panas dengan temperatur $850^{\circ} \mathrm{C}$ dan holding time 30 menit dan 60 menit menggunakan metode quenching dapat dilihat tabel dibawah ini.

Tabel 7. Tabel Hasil Uji Impact Tanpa Perlakuan Panas

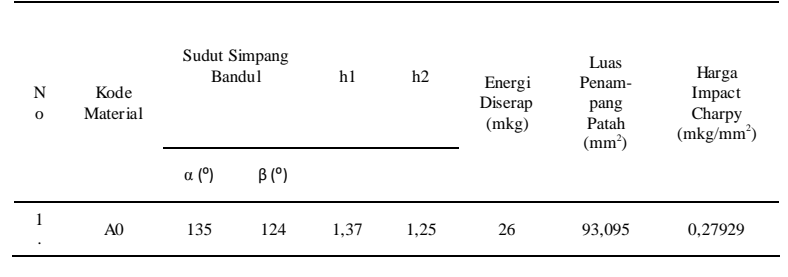

Tabel 8. Tabel Hasil Uji Impact Dengan Temperatur $850^{\circ} \mathrm{C}$ Dan Holding Time 30 Menit

\begin{tabular}{|c|c|c|c|c|c|c|c|c|}
\hline \multirow{2}{*}{$\begin{array}{l}\text { Kode } \\
\text { Material }\end{array}$} & \multicolumn{2}{|c|}{$\begin{array}{l}\text { Sudut Simpang } \\
\text { Bandul }\end{array}$} & \multirow[t]{2}{*}{ h1 } & \multirow[t]{2}{*}{ h2 } & \multirow{2}{*}{$\begin{array}{c}\text { Ener } \\
\text { gi } \\
\text { Dise } \\
\text { rap } \\
\text { (mk } \\
\text { g) }\end{array}$} & \multirow{2}{*}{$\begin{array}{c}\text { Luas } \\
\text { Penam- } \\
\text { pang } \\
\text { Patah } \\
\left(\mathrm{mm}^{2}\right)\end{array}$} & \multirow{2}{*}{$\begin{array}{c}\text { Harga } \\
\text { Impact } \\
\text { Charpy } \\
\left(\mathrm{mkg} / \mathrm{mm}^{2}\right)\end{array}$} & \multirow{2}{*}{$\begin{array}{c}\text { Harga } \\
\text { Impact } \\
\text { Charpy } \\
\text { Rata- } \\
\text { rata } \\
(\mathrm{mkg} / \mathrm{m} \\
\left.\mathrm{m}^{2}\right)\end{array}$} \\
\hline & $\alpha\left({ }^{\circ}\right)$ & $\beta\left({ }^{\circ}\right)$ & & & & & & \\
\hline B 1.1 & 135 & 133 & 1,37 & 1,35 & 3 & 85,162 & 0,03523 & \multirow{3}{*}{0,03433} \\
\hline B 1.2 & 135 & 133 & 1,37 & 1,35 & 3 & \begin{tabular}{|l|l|}
87,898 \\
\end{tabular} & 0,03413 & \\
\hline B 1.3 & 135 & 133 & 1,37 & 1,35 & 3 & 89,225 & 0,03362 & \\
\hline B 2.1 & 135 & 134 & 1,37 & 1,36 & 1,5 & 88,426 & 0,01696 & \multirow{3}{*}{0,02081} \\
\hline B 2.2 & 135 & 134 & 1,37 & 1,36 & 2 & 85,869 & 0,02329 & \\
\hline B 2.3 & 135 & 134 & 1,37 & 1,36 & 2 & 90,204 & 0,02217 & \\
\hline B 3.1 & 135 & 134 & 1,37 & 1,36 & 1 & 88,552 & 0,01129 & \multirow{3}{*}{0,01383} \\
\hline B 3.2 & 135 & 134 & 1,37 & 1,36 & 1,2 & 88,568 & 0,01355 & \\
\hline B 3.3 & 135 & 134 & 1,37 & 1,36 & 1,5 & 90,119 & 0,01664 & \\
\hline
\end{tabular}


Grafik perbandingan harga impact material tanpa perlakuan panas dengan material yang diberikan perlakuan panas pada temperatur $850^{\circ} \mathrm{C}$ dengan holding time 30 menit

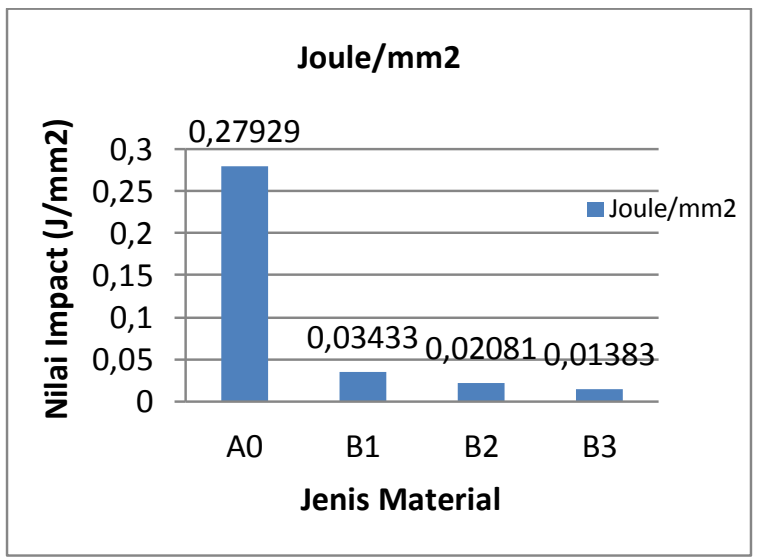

Gambar 11. Perbandingan Harga Impact

Material Tanpa Perlakuan Panas Dengan Material Yang Diberikan Perlakuan Panas Pada Temperatur $850^{\circ} \mathrm{C}$ Dengan Holding Time 30 Menit.

Material yang diberikan perlakuan panas pada temperatur $850^{\circ} \mathrm{C}$ dengan holding time 30 menit harga impact nya yaitu pada media pendingin oli sebesar $0,03433 \mathrm{~J} / \mathrm{mm}^{2}$ mengalami penurunan sebesar $87,71 \%$, media pendingin air garam sebesar $0,02081 \mathrm{~J} / \mathrm{mm}^{2}$ mengalami penurunan sebesar $92,55 \%$ dan media pendingin air sebesar $0,01383 \mathrm{~J} / \mathrm{mm}^{2}$ mengalami penurunan sebesar 95,05\%. Uji Impact dapat dilihat dalam tabel dibawah ini.

Tabel 9. Tabel Hasil Uji Impact Dengan Temperatur $850^{\circ} \mathrm{C}$ Dan Holding Time 60 Menit

\begin{tabular}{|c|c|c|c|c|c|c|c|c|}
\hline \multirow{2}{*}{$\begin{array}{l}\text { Kode } \\
\text { Material }\end{array}$} & \multicolumn{2}{|c|}{$\begin{array}{l}\text { Sudut Simpang } \\
\text { Bandul }\end{array}$} & \multirow[t]{2}{*}{ h1 } & \multirow[t]{2}{*}{ h2 } & \multirow{2}{*}{$\begin{array}{c}\text { Ener } \\
\text { gi } \\
\text { Dise } \\
\text { rap } \\
\text { (mk } \\
\mathrm{g} \text { ) }\end{array}$} & \multirow{2}{*}{$\begin{array}{l}\text { Luas Penam-pang } \\
\text { Patah }\left(\mathrm{mm}^{2}\right)\end{array}$} & \multirow{2}{*}{$\begin{array}{c}\text { Harga } \\
\text { Impact } \\
\text { Charp } \\
\text { y } \\
\left(\mathrm{mkg}^{2}\right. \\
\left.\mathrm{mm}^{2}\right)\end{array}$} & \multirow{2}{*}{$\begin{array}{c}\text { Harga } \\
\text { Impact } \\
\text { Charp } \\
\text { y } \\
\text { Rata- } \\
\text { rata } \\
\left(\mathrm{mkg}^{2}\right. \\
\left.\mathrm{mm}^{2}\right) \\
\end{array}$} \\
\hline & $\alpha\left({ }^{\circ}\right)$ & $\beta\left(0^{0}\right)$ & & & & & & \\
\hline C 1.1 & 135 & 134 & 1,37 & 1,36 & 3 & 88,139 & 0,03404 & \\
\hline C 1.2 & 135 & 134 & 1,37 & 1,36 & 2,5 & 86,818 & 0,02879 & 0,03203 \\
\hline C 1.3 & 135 & 134 & 1,37 & 1,36 & 3 & 90,160 & 0,03327 & \\
\hline C 2.1 & 135 & 135 & 1,37 & 1,37 & 1 & 92,123 & 0,01085 & \\
\hline C 2.2 & 135 & 134 & 1,37 & 1,36 & 1,3 & 88,282 & 0,01473 & \\
\hline
\end{tabular}

\begin{tabular}{cccccccc}
\hline C 2.3 & 135 & 135 & 1,37 & 1,37 & 1 & 90,528 & 0,01105 \\
\hline C 3.1 & 135 & 134 & 1,37 & 1,36 & 1,5 & 88,506 & 0,01695 \\
\hline C 3.2 & 135 & 135 & 1,37 & 1,37 & 1 & 88,509 & 0,01130 \\
\hline C 3.3 & 135 & 135 & $\begin{array}{r}1, \\
37\end{array}$ & $\begin{array}{c}1, \\
37\end{array}$ & 1 & 86,403 & $\begin{array}{c}0,0115 \\
7\end{array}$ \\
\hline
\end{tabular}

Grafik perbandingan harga impact material tanpa perlakuan panas dengan material yang diberikan perlakuan panas pada temperatur $850^{\circ} \mathrm{C}$ dengan holding time 60 menit.

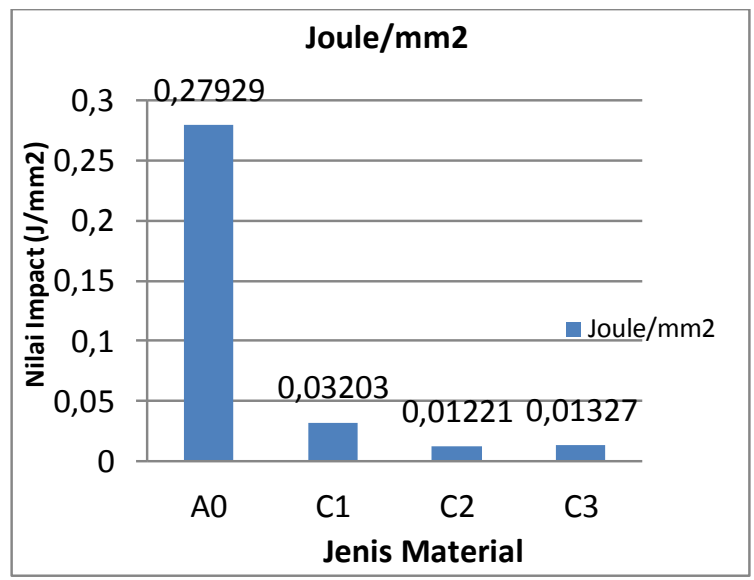

Gambar 12. Perbandingan Harga Impact Material Tanpa Perlakuan Panas Dengan Material Perlakuan Panas Pada Temperatur $850^{\circ} \mathrm{C}$ Dengan Holding Time 60 Menit.

Material yang diberikan perlakuan panas pada temperatur $850^{\circ} \mathrm{C}$ dengan holding time 60 menit harga impact nya yaitu pada media pendingin oli sebesar $0,03203 \mathrm{~J} / \mathrm{mm}^{2}$ mengalami penurunan sebesar $88,53 \%$, media pendingin air garam sebesar $0,01221 \mathrm{~J} / \mathrm{mm}^{2}$ mengalami penurunan sebesar $95,63 \%$ dan media pendingin air sebesar $0,01327 \mathrm{~J} / \mathrm{mm}^{2}$ mengalami penurunan sebesar $95,25 \%$.

Pada grafik dibawah ini akan dijelaskan perbandingan nilai uji impact yang paling tinggi pada setiap holding time nya. 


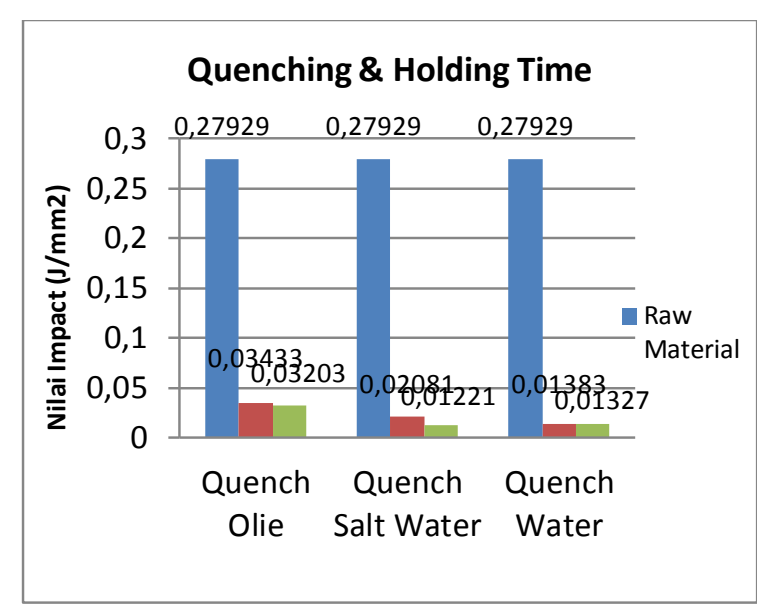

Gambar 13. Perbandingan Nilai Uji Impact Pada Setiap Holding Time Yang Berbeda Dengan Material Tanpa Perlakuan Panas.

Nilai uji impact pada setiap holding time nya pada media quenching oli, air garam, dan air. Proses perlakuan panas pada temperatur $850^{\circ} \mathrm{C}$ dengan holding time 30 menit memiliki nilai impact tertinggi sebesar $0,03433 \mathrm{~J} / \mathrm{mm}^{2}$ dan pada temperatur $850^{\circ} \mathrm{C}$ dengan holding time 60 menit sebesar $0,03203 \mathrm{~J} / \mathrm{mm}^{2}$. Nilai impact yang paling tinggi pada grafik ini yaitu pada temperatur $850^{\circ} \mathrm{C}$ dengan holding time 30 menit dan media pendingin oli.

\section{Hasil perbandingan unjuk kerja pegas daun}

Data yang diambil dari proses penuaian tebu di lahan PT. Gula Putih Mataram menggunakan pegas daun yang telah dibentuk menjadi slicer dan mengalami perlakuan panas dengan temperatur $850^{\circ} \mathrm{C}$ dan holding time 30 menit menggunakan metode quenching oli dapat dilihat pada tabel dibawah ini.

Tabel 10.Tabel Hasil Perbandingan Unjuk Kerja Terhadap Waktu Pemakaian Pisau Dan Jumlah Tebu Yang Dipanen

\begin{tabular}{cccc}
\multirow{4}{*}{ No } & Kondisi & Slicer & \\
& Pengujian & PT. Ku & Slicer Pegas Daun \\
& Lin & \\
& & \\
& & John & \\
& & Deere & John Deere 3520 \\
& Traktor yang & 3520 & Sugarcane Harvester \\
& digunakan & Sugarc & \\
& & ane & \\
& & Harves & \\
\hline
\end{tabular}

\begin{tabular}{clcc}
\hline & & ter & \\
\hline 2 & $\begin{array}{l}\text { Kecepatan maju } \\
\text { traktor }\end{array}$ & $\begin{array}{c}10 \\
\mathrm{~km} / \mathrm{ja} \\
\mathrm{m}\end{array}$ & $10 \mathrm{~km} / \mathrm{jam}$ \\
\hline 3 & $\begin{array}{l}\text { Kecepatan } 2 \\
\text { spindle utama }\end{array}$ & $\begin{array}{l}2000 \\
\mathrm{rpm}\end{array}$ & $2000 \mathrm{rpm}$ \\
\hline 4 & $\begin{array}{l}\text { Jumlah pisau } \\
\text { yang dipasang }\end{array}$ & $10 \mathrm{pcs}$ & $10 \mathrm{pcs}$ \\
\hline 5 & $\begin{array}{l}\text { Waktu sampai } \\
\text { pisau tumpul }\end{array}$ & 4 jam & 2 jam $15 \mathrm{menit}$ \\
\hline 6 & $\begin{array}{l}\text { Hasil tebu yang } \\
\text { terpotong }\end{array}$ & $\begin{array}{l}100 \\
\text { ton }\end{array}$ & \\
\hline & & & \\
\hline
\end{tabular}

Di bawah ini ditampilkan grafik perbandingan unjuk kerja terhadap waktu pemakaian pisau dan jumlah tebu yang dipanen pada slicer pegas daun dan slicer PT. Ku Lin

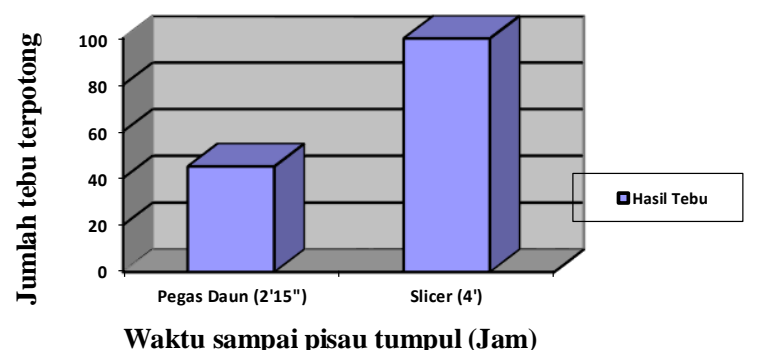

Gambar 14. Perbandingan Unjuk Kerja Slicer Terhadap Waktu Pemakaian Dan Jumlah Tebu Yang Dipanen.

Pada penelitian dengan cara membandingkan unjuk kerja pegas daun dengan slicer PT. Ku Lin terhadap biaya pengadaan slicer dan pegas daun sebagai alternatif pengganti untuk mempermudah dalam pembacaan, nilai perbandingan unjuk kerja nya dapat dilihat dalam tabel dibawah ini.

Tabel 11.Tabel Hasil Perbandingan Unjuk Kerja Terhadap Biaya Pengadaan Slicer Dan Pegas Daun Sebagai Alternatif Pengganti

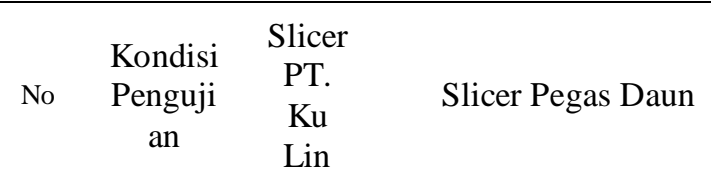




\begin{tabular}{|c|c|c|c|}
\hline 1 & $\begin{array}{l}\text { Asal } \\
\text { material }\end{array}$ & Import & $\begin{array}{l}\text { Bekas pakai truk Mitsubishi } \\
\text { 8DC9 di PT. GPM }\end{array}$ \\
\hline 2 & $\begin{array}{l}\text { Proses } \\
\text { mesin }\end{array}$ & $\begin{array}{c}\text { Tidak } \\
\text { ada } \\
\text { (siap } \\
\text { pakai) }\end{array}$ & $\begin{array}{l}\text { Bubut, Milling dan Surface } \\
\text { Grinding }\end{array}$ \\
\hline 3 & $\begin{array}{l}\text { Perlakua } \\
\text { n panas }\end{array}$ & $\begin{array}{c}\text { Tidak } \\
\text { ada } \\
\text { (siap } \\
\text { pakai) }\end{array}$ & $\begin{array}{l}\text { Suhu } 850^{\circ} \mathrm{C} \text { holding time } \\
30 \text { menit quench oli }\end{array}$ \\
\hline 4 & $\begin{array}{l}\text { Harga } \\
\text { beli/pros } \\
\text { es }\end{array}$ & $\begin{array}{c}\text { Rp. } \\
1.300 .0 \\
00 / \text { pcs }\end{array}$ & \pm Rp. $200.000 /$ pcs \\
\hline
\end{tabular}

Berikut ditampilkan grafik perbandingan unjuk kerja terhadap biaya pengadaan slicer dan pegas daun sebagai alternatif pengganti.

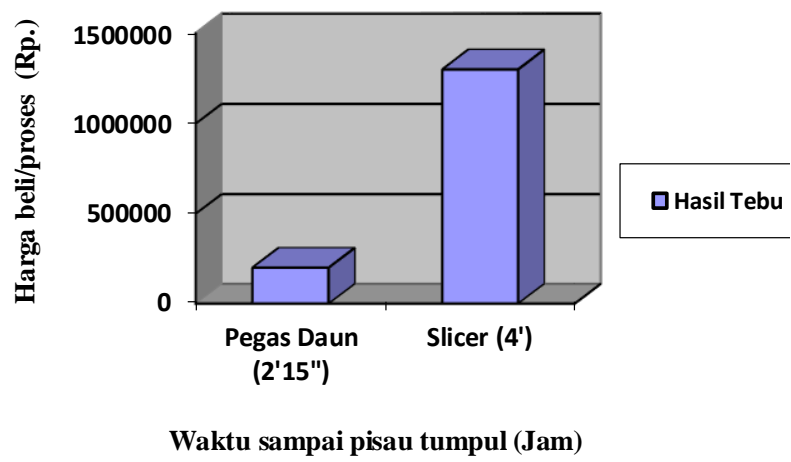

Gambar 15. Perbandingan Unjuk Kerja Slicer Terhadap Biaya Pengadaan Dan Pegas Daun Sebagai Alternatif Pengganti.

\section{Kesimpulan}

Dari penelitian ini dapat disimpulkan bahwa :

1. Pengaruh holding time pada proses heat treatment terhadap kekerasan dari pegas daun yaitu pada temperatur $850^{\circ} \mathrm{C}$ dengan holding time 30 menit untuk nilai kekerasan yang terbaik adalah 794 VHN meningkat dari 475 VHN.

2. Pengaruh holding time pada proses heat treatment terhadap kekuatan impact dari pegas daun yaitu pada temperatur $850^{\circ} \mathrm{C}$ dengan holding time 30 menit untuk kekuatan impact yang terbaik adalah $0,03433 \mathrm{~J} / \mathrm{mm}^{2}$ mengalami penurunan dari 0,27929 $\mathrm{J} / \mathrm{mm}^{2}$.
3. Pengaruh media pendingin pada proses heat treatment terhadap kekerasan dari pegas daun yaitu pada temperatur $850^{\circ} \mathrm{C}$ dengan media pendingin air untuk nilai kekerasan yang terbaik adalah 794 VHN mengalami kenaikan $67,16 \%$.

4. Pengaruh media pendingin pada proses heat treatment terhadap kekuatan impact dari pegas daun yaitu pada temperatur $850^{\circ} \mathrm{C}$ dengan media pendingin oli untuk nilai kekuatan impact yang terbaik adalah 0,03433 $\mathrm{J} / \mathrm{mm}^{2}$ mengalami penurunan $87,71 \%$.

5. Pengaruh holding time ideal dan media pendingin yang paling optimal pada proses heat treatment terhadap kekerasan dari pegas daun yaitu pada temperatur $850^{\circ} \mathrm{C}$ dengan holding time 30 menit dan media pendingin air untuk nilai kekerasan yang terbaik adalah 794 VHN meningkat dari 475 VHN atau meningkat $67,16 \%$.

6. Pengaruh holding time ideal dan media pendingin yang paling optimal pada proses heat treatment terhadap kekuatan impact dari pegas daun yaitu pada temperatur $850^{\circ} \mathrm{C}$ dengan holding time 30 menit dan media pendingin oli untuk nilai kekuatan impact yang terbaik adalah $0,03433 \mathrm{~J} / \mathrm{mm}^{2}$ menurun dari $0,27929 \mathrm{~J} / \mathrm{mm}^{2}$ atau menurun sampai $87,71 \%$.

Sehingga oli adalah media yang paling optimal untuk perubahan sifat mekanik pegas daun truk bekas.

7. Perbandingan unjuk kerja antara slicer dari PT. Ku Lin dan slicer dari pegas daun bekas Mitsubishi 8DC9 pada kondisi operasional yang sama, kecepatan maju mesin $10 \mathrm{~km} / \mathrm{jam}$ dan kecepatan 2 buah spindle utama yang masing-masing terdiri dari 5 buah slicer dari pegas daun adalah 2000 rpm. Maka ditemukan hasil pengujian langsung bahwa slicer yang berjumlah 10 buah untuk setiap proses penuaian hanya dapat bertahan selama 2 jam 15 menit dengan hasil kurang lebih 45 ton, setelah itu slicer harus diganti 
karena sudah mengalami kerusakan dan keausan.

\section{Referensi}

[1] Arief Murtiono. (2012). "Pengaruh Quenching Dan Tempering Terhadap Kekerasan Dan Kekuatan Tarik Serta Struktur Mikro Baja Karbon Sedang Untuk Mata Pisau Pemanen Sawit". Jurnal e-Dinamis Volume 2. No 2 September 2012. Medan: Universitas Sumatra Utara.

[2] Bambang Tri Wibowo. (2006). "Pengaruh Temper Dengan Quenching Media Pendingin Oli Mesran SAE 40 Terhadap Sifat Fisis Dan Mekanis Baja ST 60". Skripsi. Semarang: Pendidikan Teknik Mesin S1 Universitas Negeri Semarang.

[3] Purboputro, P. Ilmu. 2009. Peningkatan Kekuatan Pegas Daun dengan Cara Quenching. Jurnal Media Mesin Volume 10 Nomor 1 Hal.18 ISSN 1411-4348.

[4] Groenendijk, G; Van Der Linde, J.; Sachri, S. (Alih Bahasa), 1984, Pengujian Material, Cetakan ke-1, CV. Binacipta, Jakarta

[5] Lawrence H. Van Vlack. (1992). "Ilmu Dan Teknologi Bahan". Michigan : University Of Michigan.

[6] Margono (2008). "Pengaruh Perbedaan Waktu Penahan Suhu Stabil (Holding Time) Trhadap Kekerasan Logam”. Jurnal Litbang Provinsi Jawa Tengah, Volume 6 N0. 2. Desember 2008. Staf Pengajar D3 Fakultas Teknik UNDIP, Semarang.

[7] Muhammad Zuchry M, (2012). "Pengaruh Temperatur Dan Bentuk Takikan Terhadap Kekuatan Impak Logam”. MEKTEK Tahun XIV No.1, Januari 2012. Staff Pengajar Jurusan
Teknik Mesin: Universitas Tadulako, Palu.

[8] Nukman. (2009). "Ketangguhan Beban Impak Dan Beban Tarik Maksimum Pada Pelat Baja Berlapis Akibat Quenching Dan Normalizing". Jurnal Rekayasa Mesin Volume 9. No 3, Nopember 2009.: Jurusan Teknik Mesin S1 Universitas Sriwijaya Palembang.

[9] "Pedoman Penulisan Karya Ilmiah". Unversitas Muhammadiyah Metro. (2016).

[10] Persson, S. (1987). Mechanics of Cutting Plant Material. Michigan: America Society of Agricultural Engineers.

[11] Pramuko Ilmu Purboputro. (2009). "Peningkatan Kekakuan Pegas Daun Dengan Cara Quenching". Media Mesin Volume 10. No 1, Januari 2009, 15-21 ISSN 1411-4348. Surakarta: Universitas Muhammadiyah Surakarta.

[12] Rabiatul Adawiyah, Murdjani, Anang Hendrawan. (2014). "Pengaruh Perbedaan Media Pendingin Terhadap Struktur Mikro Dan Kekerasan Pegas Daun Dalam Proses Hardening". Jurnal POROS TEKNIK, Volume 6, No. 2, Desember 2014 : 55-102. Staff Pengajar Jurusan Teknik Mesin: Politeknik Negeri Banjarmasin.

[13] Rubijanto. (2006). "Pengaruh Proses Pendinginan Paska Perlakuan Panas Terhadap Uji Kekerasan (Vickers) Dan Uji Tarik Pada Baja Tahan Karat 304 Produksi Pengecoran Logam Di Klaten". Traksi. Vol. 4. No. 1. Juni 2006.

[14] Schonmetz, Alois Karl Gruber. 1985. Pengetahuan Bahan Dalam 
Pengerjaan Logam. Alih Bahasa: Hardjapamekas Eddy D. DiplomIng. Angkasa, Bandung,

[15] Syafriandi, 2016, Pengujian Kedalaman Kepras Dengan Menggunakan Alat Kepras Traktor Roda Dua Pada Tebu Ratoon, Pertanian Terpadu dan Berkelanjutan Berbasis Sumber Daya dan Kearifan Lokal di Era Masyarakat Ekonomi Asean (MEA), Seminar Nasional Dies Natalis ke-33 Fakultas Pertanian Universitas Sriwijaya, Palembang, 14 September 2016, Palembang, Fakultas Pertanian Universitas Sriwijaya, , 978-979-8389-24-5.

[16] Suparjo. Purnomo. (2012). Variasi Temperatur Pemanasan Pada Proses Perlakuan Panas Terhadap Kekerasan Dengan Material SS-304L. Jurnal IPTEK Vol. 16 No. 2 Desember 2012. Surabaya: Institut Teknologi Adhi Tama Surabaya.

[17] Budianto, E., Choiron, M. A., \& Darmadi, D. B. (2016). Hardening Baja AISI 1045 Menggunakan Gel Aloe Vera Sebagai Media Pendingin. Rekayasa Mesin, 7(2), 5564. 